\title{
Generalized Inverse Pada Matriks Atas $Z_{n}$
}

\author{
Corry Corazon Marzuki ${ }^{1}$, Yulia Rosita ${ }^{2}$ \\ 'Jurusan Matematika, Fakultas Sains dan Teknologi, UIN Sultan Syarif Kasim Riau \\ Jl. HR. Soebrantas No. 155 Simpang Baru, Panam, Pekanbaru, 28293 \\ E-mail: corrazon_m@yahoo.co.id@uin-suska.ac.id,Yuliarosita21@yahoo.com@uin-suska.ac.id.
}

\begin{abstract}
ABSTRAK
Suatu matriks mempunyai invers apabila matriks tersebut non-singular dan bujur sangkar. Namun, apabila matriks tersebut singular atau tidak bujur sangkar, inversnya masih dapat ditentukan dengan generalized inverse. Pada tugas akhir ini dibahas bagaimana menentukan generalized inverse pada matriks atas $Z_{n}$ menggunakan aturan algoritma dan aturan pendiagonalan matriks. Berdasarkan pembahasan pada tugas akhir ini dapat disimpulkan bahwa apabila $n$ merupakan bilangan prima maka $Z_{n}$ adalah lapangan dan matriks atas $Z_{n}$ pasti mempunyai generalized inverse. Namun apabila $n$ bukan bilangan prima maka $Z_{n}$ adalah ring komutatif dengan elemen satuan dan matriks atas $Z_{n}$ mempunyai generalized inverse apabila dalam proses pengerjaan tidak dibutuhkan invers dari suatu elemen atas $Z_{n}$ yang tidak mempunyai invers terhadap perkalian. Adapun generalized inverse yang diperoleh adalah tidak tunggal.
\end{abstract}

Kata kunci: Bilangan Bulat Modulo n, Generalized Inverse, Lapangan, Rank, Ring

\section{ABSTRACT}

A matrix has an inverse if the matrix is non-singular and square. However, if the matrix is singular or not square, inverse still can be determined with the generalized inverse. In this thesis discussed how to determine the inverse matrix of $\boldsymbol{Z}_{n}$ using the rules diagonalizing matrix and algorithms rules. The result of this research is that if $\boldsymbol{n}$ is a prime then $\boldsymbol{Z}_{\boldsymbol{n}}$ is a field and the matrix over $\boldsymbol{Z}_{\boldsymbol{n}}$ has a generalized inverse. However if $\boldsymbol{n}$ is not prime then $\boldsymbol{Z}_{\boldsymbol{n}}$ is commutative ring with unity, and the matrix over $\boldsymbol{Z}_{\boldsymbol{n}}$ has a generalized inverse if in the process is not needed inverse of an element over $\boldsymbol{Z}_{\boldsymbol{n}}$ has no multiplicative inverse. The generalized inverse was not obtained in a single.

KeyWords: Field, Generalized Inverse, Integer Modulo n, Rank, Ring.

\section{Pendahuluan}

Salah satu jenis himpunan matriks adalah himpunan dari matriks atas lapangan, $M_{m \times n}(F)$. Selain himpunan dari matriks atas lapangan, ada juga himpunan dari matriks yang entri-entrinya elemen ring komutatif, yang disebut dengan himpunan dari semua matriks atas ring komutatif, $M_{m \times n}(R)$.

Dalam perhitungan matriks terdapat beberapa operasi matriks, antara lain penjumlahan matriks, perkalian matriks, determinan dari matriks dan menentukan invers dari matriks. Suatu matriks mempunyai invers apabila matriks itu merupakan matriks bujur sangkar dan non singular. Dengan kata lain bahwa hanya matriks bujur sangkar dan non singular yang memiliki invers. Berdasarkan jurnal yang berjudul "A Generalized Inverse for Matrices" karangan R. Penrose Tahun 1954 bahwasanya bukan hanya matriks bujur sangkar yang mempunyai invers, tetapi matriks yang tidak bujur sangkar atau singular juga mempunyai invers yang disebut generalized inverse. 
Generalized inverse telah banyak yang dibahas dan diteliti diantaranya, Jeff Gill and King dalam jurnal yang berjudul "What is the Generalized Inverse of a Matrix?" yang telah membahas mengenai menentukan generalized inverse pada matriks. Selanjutnya, I.A Adetunde, dkk tahun 2010 dalam jurnal yang berjudul "On The Generalized Inverse of a Matrix" yang membahas tentang menentukan generalized inverse pada matriks singular dan matriks bujur sangkar serta penerapannya pada sistem persamaan linear. Selanjutnya penelitian yang sudah dilakukan oleh Desi Murnita (2012), yakni tentang "Penyelesaian Invers Matriks Menggunakan Metode Generalized Inverse", yang membahas bagaimana menentukan generalized inverse dari matriks yang tidak bujur sangkar berukuran $m \times n$ dan matriks bujur sangkar yang berukuran $n \times n$ yang singular.

Pada penelitian ini mengemukakan tentang bagaimana menentukan generalized inverse dari matriks yang tidak bujur sangkar berukuran $m \times n$ dan matriks bujur sangkar yang berukuran $n \times n$ yang singular atas $Z_{n}$.

Dalam penelitian ini bertujuan untuk mendapatkan langkah-langkah penyelesaian generalized inverse pada matriks atas $Z_{n}$ dengan aturan pendiagonalan matriks dan algoritma.

\section{Metode Penelitian}

Metode yang digunakan dalam penelitian ini adalah studi literatur yaitu dengan mengumpulkan data dan informasi dari berbagai sumber seperti jurnal-jurnal, atau makalah-makalah dan buku-buku yang bersangkutan.

Jalannya penelitian dapat ditunjukkan pada Gambar 1 dibawah ini:

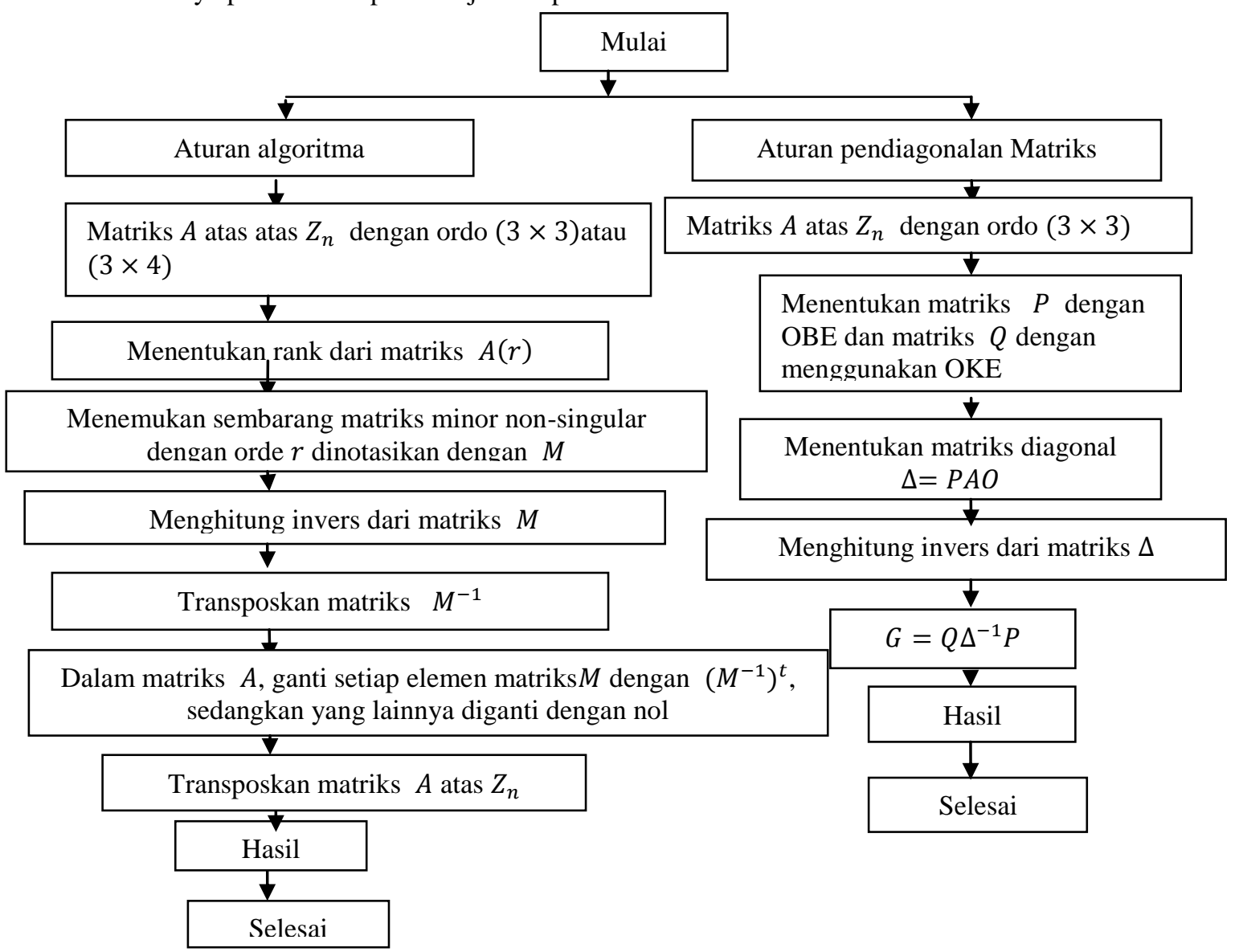

Gambar 1 Flowchart Metodologi Penelitian 


\section{Generarlized Inverse}

\section{Hasil Dan Pembahasan}

Selama ini yang diketahui matriks yang memiliki invers adalah matriks bujur sangkar dan non singular. Akan tetapi bila diberikan permasalahan untuk matriks yang tidak bujur sangkar atau singular, maka kita dapat menentukan invers dari matriks tersebut yang dinamakan generalized inverse.

Definisi 1. (J.Otero, 1998): Jika $A$ adalah matriks berukuran $m \times n$, maka $G$ adalah generalized inverse dari $A$ dengan ukuran matriks $n \times m$ apabila berlaku $A G A=A$. Adapun matriks $G$ ini tidak tunggal. Ada dua cara yang digunakan untuk menemukan generalized inverse dari sebuah matriks yaitu : 1. Aturan algoritma.

2. Aturan pendiagonalan matriks.

\section{Ring (Gelanggang)}

Apabila himpunan tak kosong $R$ terhadap operasi penjumlahan dan perkalian merupakan ring, maka ditulis $\left(R,+,,^{\circ}\right)$ suatu ring, atau lebih singkat disebut $R$ ring.

Definisi 2. (Jimmie Gilbert dan Linda Gilbert,1992): Diberikan himpunan tak kosong $R$ disebut ring (gelanggang) atas operasi penjumlahan $(+)$ dan perkalian $(\cdot)$, jika memenuhi sifat :

1. Untuk setiap $x, y \in R$ maka berlaku $x+y \in R \quad$ (sifat tertutup).

2. Untuk setiap $x, y, z \in R$ maka berlaku $(x+y)+z=x+(y+z) \quad$ (sifat assosiatif).

3. Terdapat $\mathrm{e} \in R$ sehingga untuk setiap $x \in R$ berlaku bahwa $x+e=e+x=x$ (eksistensi elemen identitas).

4. Untuk setiap $x \in R$, terdapat $(-x) \in R$ sehingga $x+(-x)=(-x)+x=e$ (eksistensi elemen invers).

5. Untuk setiap $x, y \in R$ berlaku $x+y=y+x$ (bersifat komutatif)

6. Untuk setiap $x, y \in R$ maka $x \cdot y \in R$ (tertutup).

7. Untuk setiap $x, y, z \in R$ berlaku $(x \cdot y) \cdot z=x \cdot(y \cdot z) \quad$ (sifat assosiatif).

8. untuk setiap $x, y, z \in R$ berlaku $x \cdot(y+z)=x \cdot y+x \cdot z$ (distributif kanan) dan $(x+y) \cdot z=$ $x \cdot z+y \cdot z$ (distributif kiri).

Definisi 3. (Jimmie Gilbert dan Linda Gilbert,1992): Diberikan suatu ring $R$. Jika terdapat $e \in R$ sehingga untuk setiap $x \in R$ berlaku $x \cdot e=e \cdot x=x$ maka $e \in R$ disebut elemen satuan dan $R$ dikatakan sebagai ring dengan elemen satuan. Jika terhadap perkalian $R$ bersifat komutatif, maka $R$ disebut ring komutatif.

Definisi 4. (Jimmie Gilbert dan Linda Gilbert,1992): Diberikan suatu ring $R$ dengan $e$ elemen satuan, dan diberikan $a \in R$. Jika $x \in R$ berlaku $a \cdot x=x \cdot a=e$, maka $x$ adalah invers perkalian dari $a$.

\section{Lapangan}

Suatu lapangan adalah tipe dari ring. Adapun definisi dari lapangan dapat di lihat di bawah ini:

Definisi 5. (Jimmie Gilbert dan Linda Gilbert,1992): Diberikan $F$ suatu ring. Maka $F$ adalah sebuah lapangan jika memenuhi sifat :

1. $F$ adalah ring komutatif.

2. $F$ mempunyai elemen satuan $e$, dan $e \neq 0$.

3. Setiap elemen tak nol dari $F$ mempunyai invers perkalian.

Bilangan rasional, bilangan real, dan bilangan kompleks adalah contoh dari lapangan. Kita akan melihat di akibat 2.1 bahwa jika $n$ adalah bilangan prima, maka $Z_{n}$ adalah lapangan.

Akibat 6. (Jimmie Gilbert dan Linda Gilbert,1992): $Z_{n}$ adalah sebuah lapangan jika dan hanya jika $n$ adalah bilangan prima. 
Dalam contoh yang akan digunakan di bawah ini, perhitungan yang akan dilakukan kita menggunakan matriks yang entri-entrinya anggota dari himpunan $Z_{5}$ dan $Z_{6}$. Adapun perbedaan dari $M_{Z_{5}}$ dan $M_{Z_{6}}$ tersebut dapat di lihat dari penyelesaian di bawah ini.

\section{Menentukan Generalized Inverse pada Matriks atas $Z_{n}$ Menggunakan Aturan}

Algoritma

Berikut ini akan diberikan contoh matriks bujur sangkar atas $Z_{5}$ berordo $3 \times 3$ untuk menentukan generalized inverse dengan menggunakan aturan algoritma. $Z_{5}$ ini sudah terbukti lapangan, karena telah memenuhi sifat-sifat lapangan.

\section{Contoh 1:}

Tentukan generalized inverse dari matriks $A=\left[\begin{array}{lll}2 & 4 & 0 \\ 2 & 1 & 3 \\ 1 & 0 & 2\end{array}\right] \in M_{Z_{5}}$ menggunakan aturan algoritma.

\section{Penyelesaian :}

Akan ditentukan rank dari matriks $A$ sebagai berikut :

$$
\begin{aligned}
& {\left[\begin{array}{lll}
2 & 4 & 0 \\
2 & 1 & 3 \\
1 & 0 & 2
\end{array}\right] b_{1} \leftrightarrow b_{3}} \\
& {\left[\begin{array}{lll}
1 & 0 & 2 \\
2 & 1 & 3 \\
2 & 4 & 0
\end{array}\right] b_{2}+3 b_{1}} \\
& {\left[\begin{array}{lll}
1 & 0 & 2 \\
0 & 1 & 4 \\
0 & 4 & 1
\end{array}\right] b_{3}+b_{1}} \\
& {\left[\begin{array}{lll}
1 & 0 & 2 \\
0 & 1 & 4 \\
0 & 0 & 0
\end{array}\right]}
\end{aligned}
$$

Jadi rank dari matriks $A$ adalah 2 .

Adapun langkah-langkah untuk menentukan generalized inverse dengan menggunakan aturan algoritma adalah sebagai berikut:

a. Diberikan matriks $A$ dengan ordo $3 \times 3$ dengan $r k(A)=2$, temukan sembarang matriks minor non-singular dengan orde 2. Notasikan dengan $M_{1}$ :

$$
M_{1}=\left[\begin{array}{ll}
2 & 4 \\
2 & 1
\end{array}\right]
$$

b. $\quad$ Menemukan invers matriks $M_{1}$, yaitu $M_{1}^{-1}$ kemudian tranposkan $\left(M_{1}^{-1}\right)^{t}$ :

$$
\begin{array}{r}
M_{1}^{-1}=\left[\begin{array}{ll}
4 & 4 \\
2 & 3
\end{array}\right] \\
\left(M_{1}{ }^{-1}\right)^{t}=\left[\begin{array}{ll}
4 & 2 \\
4 & 3
\end{array}\right]
\end{array}
$$

c. Dalam matriks $A$, diganti setiap elemen matriks $M_{1}$ dengan elemen matriks $\left(M_{1}{ }^{-1}\right)^{t}$ dan ganti elemen lainnya dengan nol, yaitu :

$$
A=\left[\begin{array}{lll}
4 & 2 & 0 \\
4 & 3 & 0 \\
0 & 0 & 0
\end{array}\right]
$$

d. Transposkan matriks $A$, diperoleh: 


$$
A^{t}=\left[\begin{array}{lll}
4 & 4 & 0 \\
2 & 3 & 0 \\
0 & 0 & 0
\end{array}\right]
$$

e. Hasilnya berupa matriks $G_{1}$, generalized inverse dari matriks $A$ adalah:

$$
G_{1}=\left[\begin{array}{lll}
4 & 4 & 0 \\
2 & 3 & 0 \\
0 & 0 & 0
\end{array}\right]
$$

Matriks $G_{1}$ ini merupakan salah satu generalized inverse dari matriks $A$.

Selanjutnya akan ditunjukkan $G_{1}$ adalah generalized inverse dari $A$ apabila berlaku $A G_{1} A=A$,

$$
A G_{1} A=\left[\begin{array}{lll}
2 & 4 & 0 \\
2 & 1 & 3 \\
1 & 0 & 2
\end{array}\right]\left[\begin{array}{lll}
4 & 4 & 0 \\
2 & 3 & 0 \\
0 & 0 & 0
\end{array}\right]\left[\begin{array}{lll}
2 & 4 & 0 \\
2 & 1 & 3 \\
1 & 0 & 2
\end{array}\right]=\left[\begin{array}{lll}
2 & 4 & 0 \\
2 & 1 & 3 \\
1 & 0 & 2
\end{array}\right]
$$

Jadi, terbukti $A G_{1} A=A, G_{1}$ adalah generalized inverse dari matriks $A$.

Dengan langkah-langkah yang sama, akan ditemukan generalized inverse yang lainnya pada matriks $A$. Dengan ditunjukkan $A G A=A, G$ adalah generalized inverse dari matriks $A$ atas $Z_{5}$. Dari hasil di atas dapat dilihat bahwa generalized inverse dari matriks $A$ atas $Z_{5}$ adalah tidak tunggal. Maka dari itu himpunan $Z_{5}$ merupakan lapangan.

\section{Contoh 2 :}

Berikut ini akan diberikan contoh matriks atas $Z_{6}$ yang berordo $3 \times 4$ untuk menentukan generalized inverse. $Z_{6}$ ini sudah terbukti ring komutatif dengan elemen satuan, karena telah memenuhi sifat-sifat ring komutatif dengan elemen satuan.

Tentukan generalized inverse dari matriks $B=\left[\begin{array}{cccc}1 & 0 & 5 & 4 \\ 5 & 1 & 3 & 5 \\ 1 & 2 & 5 & 1\end{array}\right] \in M_{Z_{6}}$ dengan menggunakan aturan algoritma.

\section{Penyelesaian :}

Akan ditentukan rank dari matriks $B$ sebagai berikut :

$$
\begin{aligned}
& {\left[\begin{array}{llll}
1 & 0 & 5 & 4 \\
5 & 1 & 3 & 5 \\
1 & 2 & 5 & 1
\end{array}\right] \begin{array}{c}
b_{2}+b_{1} \\
b_{3}+5 b_{1}
\end{array}} \\
& {\left[\begin{array}{llll}
1 & 0 & 5 & 4 \\
0 & 1 & 2 & 3 \\
0 & 2 & 0 & 3
\end{array}\right]}
\end{aligned}
$$

Jadi rank dari matriks $B$ adalah 3 .

Adapun langkah-langkah untuk menentukan generalized inverse dengan menggunakan aturan algoritma adalah sebagai berikut: 
a. Diberikan matriks $B$ dengan ordo $3 \times 3$ dengan $r k(B)=3$, temukan sembarang matriks minor non-singular dengan orde 3 . Notasikan dengan $M_{1}$,

$$
M_{1}=\left[\begin{array}{lll}
0 & 5 & 4 \\
1 & 3 & 5 \\
2 & 5 & 1
\end{array}\right]
$$

b. Temukan invers matriks $M_{1}$, yaitu $M_{1}^{-1}$ kemudian tranposkan $\left(M_{1}^{-1}\right)^{t}$, untuk mencari invers matriks $M_{1}$ diperoleh dari operasi baris elementer.

$$
\begin{aligned}
M_{1}{ }^{-1} & =\left[\begin{array}{lll}
4 & 3 & 5 \\
3 & 2 & 2 \\
1 & 2 & 2
\end{array}\right] \\
\left(M_{1}{ }^{-1}\right)^{t} & =\left[\begin{array}{lll}
4 & 3 & 1 \\
3 & 2 & 2 \\
5 & 2 & 5
\end{array}\right]
\end{aligned}
$$

c. Dalam matriks $B$, diganti setiap elemen matriks $M_{1}$ dengan elemen matriks $\left(M_{1}{ }^{-1}\right)^{t}$ dan ganti elemen lainnya dengan nol, yaitu :

$$
B=\left[\begin{array}{llll}
0 & 4 & 3 & 1 \\
0 & 3 & 2 & 2 \\
0 & 5 & 2 & 5
\end{array}\right]
$$

d. Transposkan matriks $B$, diperoleh:

$$
B^{t}=\left[\begin{array}{lll}
0 & 0 & 0 \\
4 & 3 & 5 \\
3 & 2 & 2 \\
1 & 2 & 5
\end{array}\right]
$$

e. Hasilnya berupa matriks $G_{1}$, generalized inverse dari matriks $B$ adalah:

$$
G_{1}=\left[\begin{array}{lll}
0 & 0 & 0 \\
4 & 3 & 5 \\
3 & 2 & 2 \\
1 & 2 & 5
\end{array}\right]
$$

Matriks $G_{1}$ ini merupakan salah satu generalized inverse dari matriks $B$.

Selanjutnya akan ditunjukkan $G_{1}$ adalah generalized inverse dari $B$ apabila berlaku $B G_{1} B=B$.

$$
B G_{1} B=\left[\begin{array}{llll}
1 & 0 & 5 & 4 \\
5 & 1 & 3 & 5 \\
1 & 2 & 5 & 1
\end{array}\right]\left[\begin{array}{lll}
0 & 0 & 0 \\
4 & 3 & 5 \\
3 & 2 & 2 \\
1 & 2 & 5
\end{array}\right]\left[\begin{array}{llll}
1 & 0 & 5 & 4 \\
5 & 1 & 3 & 5 \\
1 & 2 & 5 & 1
\end{array}\right]=\left[\begin{array}{llll}
1 & 0 & 5 & 4 \\
5 & 1 & 3 & 5 \\
1 & 2 & 5 & 1
\end{array}\right]
$$

Jadi, terbukti $B G_{1} B=B, G_{1}$ adalah generalized inverse dari matriks $B$.

Dengan langkah-langkah yang sama, akan di tunjukkan generalized inverse yang lainnya, yaitu :

a. Diberikan matriks $B$ dengan ordo $3 \times 3$ dengan $r k(B)=3$, temukan sembarang matriks minor non-singular dengan orde 3 . Notasikan dengan $M_{2}$, 


$$
M_{2}=\left[\begin{array}{lll}
1 & 0 & 5 \\
5 & 1 & 3 \\
1 & 2 & 5
\end{array}\right]
$$

b. Temukan invers matriks $M_{2}$, yaitu $M_{2}^{-1}$ kemudian tranposkan $\left(M_{2}{ }^{-1}\right)^{t}$, untuk mencari invers matriks $M_{2}$ diperoleh dari operasi baris elementer.

$$
\begin{aligned}
& {\left[\begin{array}{lll|lll}
1 & 0 & 5 & 1 & 0 & 0 \\
5 & 1 & 3 & 0 & 1 & 0 \\
1 & 2 & 5 & 0 & 0 & 1
\end{array}\right] b_{2}+b_{1}} \\
& {\left[\begin{array}{lll|lll}
1 & 0 & 5 & 1 & 0 & 0 \\
0 & 1 & 2 & 1 & 1 & 0 \\
0 & 2 & 0 & 5 & 0 & 1
\end{array}\right] b_{3}+4 b_{2}} \\
& {\left[\begin{array}{lll|lll}
1 & 0 & 5 & 1 & 0 & 0 \\
0 & 1 & 2 & 1 & 1 & 0 \\
0 & 0 & 2 & 3 & 4 & 1
\end{array}\right]\left(2^{-1}\right) b_{3}}
\end{aligned}
$$

Matriks $M_{2}$ di atas tidak dapat dicari generalized inverse nya karena $2 \in Z_{6}$ tidak mempunyai invers terhadap perkalian pada $Z_{6}$, sehingga matriks $M_{2}$ tidak mempunyai generalized inverse.

\section{Menentukan Generalized Inverse pada Matriks Atas $Z_{n}$ Menggunakan Aturan Pendiagonalan Matriks}

\section{Contoh 3:}

Tentukan generalized inverse dari matriks $A=\left[\begin{array}{lll}2 & 4 & 0 \\ 2 & 1 & 3 \\ 1 & 0 & 2\end{array}\right] \in M_{Z_{5}}$ menggunakan aturan pendiagonalan matriks.

\section{Penyelesaian :}

Adapun langkah-langkah untuk menentukan generalized inverse dengan menggunakan aturan pendiagonalan matriks adalah sebagai berikut :

a. Diketahui matriks $A$ ordo $3 \times 3$. Akan dicari matriks $P$ dengan melakukan operasi baris elementer (OBE).

Sehingga diperoleh matriks $P$ :

$$
P=\left[\begin{array}{lll}
0 & 0 & 1 \\
0 & 1 & 3 \\
1 & 1 & 1
\end{array}\right] .
$$

Selanjutnya akan dicari untuk matriks $Q$ dengan melakukan operasi elementer kolom (OKE).

Sehingga diperoleh matriks $Q$ :

$$
Q=\left[\begin{array}{lll}
1 & 0 & 3 \\
0 & 1 & 1 \\
0 & 0 & 1
\end{array}\right]
$$


b. Setelah didapatkan matriks $P$ dan matriks $Q$, selanjutnya akan ditentukan matriks $\Delta$ dengan menggunakan persamaan $\Delta=P A Q$, yaitu :

$$
\begin{gathered}
\Delta=P A Q \\
\Delta=\left[\begin{array}{lll}
1 & 0 & 0 \\
0 & 1 & 0 \\
0 & 0 & 0
\end{array}\right]
\end{gathered}
$$

c. Kemudian akan dicari invers matriks $\Delta^{-}$sehingga diperoleh:

$$
\Delta^{-}=\left[\begin{array}{lll}
1 & 0 & 0 \\
0 & 1 & 0 \\
0 & 0 & 0
\end{array}\right]
$$

d. Selanjutnya akan ditentukan matriks $G_{1}$ yaitu $G_{1}=Q \Delta^{-} P$, yaitu :

$$
\begin{aligned}
G_{1} & =Q \Delta^{-} P \\
G_{1} & =\left[\begin{array}{lll}
0 & 0 & 1 \\
0 & 1 & 3 \\
0 & 0 & 0
\end{array}\right]
\end{aligned}
$$

Selanjutnya akan ditunjukkan $G_{1}$ adalah generalized inverse dari $A$ apabila berlaku $A G_{1} A=A$.

$$
A G_{1} A=\left[\begin{array}{lll}
2 & 4 & 0 \\
2 & 1 & 3 \\
1 & 0 & 2
\end{array}\right]\left[\begin{array}{lll}
0 & 0 & 1 \\
0 & 1 & 3 \\
0 & 0 & 0
\end{array}\right]\left[\begin{array}{lll}
2 & 4 & 0 \\
2 & 1 & 3 \\
1 & 0 & 2
\end{array}\right]=\left[\begin{array}{lll}
2 & 4 & 0 \\
2 & 1 & 3 \\
1 & 0 & 2
\end{array}\right]
$$

Jadi, terbukti $A G_{1} A=A, G_{1}$ adalah generalized inverse dari matriks $A$. Matriks $G_{1}$ ini tidak tunggal. Untuk menentukan generalized inverse lainnya dengan langkah-langkah yang sama.

\section{Kesimpulan}

Berdasarkan hasil penelitian yang dilakukan, maka diperoleh suatu invers dari matriks atas $Z_{n}$ dengan metode generalized inverse, terdapat dua aturan yaitu algoritma dan aturan pendiagonalan matriks. Sehingga dapat diperoleh beberapa kesimpulan adalah sebagai berikut:

1. Apabila $\boldsymbol{n}$ merupakan bilangan prima, maka $\boldsymbol{Z}_{\boldsymbol{n}}$ adalah lapangan dan matriks atas $\boldsymbol{Z}_{\boldsymbol{n}}$ pasti mempunyai generalized inverse.

2. Apabila $\boldsymbol{n}$ bukan bilangan prima, maka $\boldsymbol{Z}_{\boldsymbol{n}}$ adalah ring komutatif dengan elemen satuan.

3. Apabila $\boldsymbol{n}$ bukan bilangan prima, maka matriks atas $\boldsymbol{Z}_{\boldsymbol{n}}$ mempunyai generalized inverse jika dalam pengerjaan tidak dibutuhkan invers dari suatu elemen atas $\boldsymbol{Z}_{\boldsymbol{n}}$ yang tidak mempunyai invers terhadap perkalian.

\section{Daftar Pustaka}

[1] Adi, Ben-Israel, N.E. Greville, Thomas. 1973. Generalized Inverse Theory and Application. Second Edition, Canadian Mathematical Society Societe mathematique du canada.

[2] Anton, Howard dan Rorres, Chriss. 2004. Aljabar Linear Elementer Versi Aplikasi Edisi Kedelapan. Erlangga. Jakarta.

[3] Anton, Howard. 2000. Dasar-dasar Aljabar Linier, Jilid 1. Interaksara. Batam Center. 
[4] Gilbert, Jimmie, dan Gilbert Linda. 1992. Elements of Modern Algebra. KENT Publishing Company. Boston.

[5] Jacob, B. 1990. Linear Algebra. W. H. Freeman and Company. New York.

[6] Murnita, Desi. 2012. Penyelesaian Invers Matriks Menggunakan Metode Generalized Inverse. Skripsi. UIN SUSKA RIAU. Pekanbaru.

[7] Otero,J. 1998. Generalized Inverse matrices and the Gauss-Markov Theorema, Seccion Departamental de Astronomia y Geodesia Universidad Complutense de Madrid. Publicacion num 192.

[8] Ruminta. 2009. Matriks Persamaan Linier dan Pemograman Linier. Rekayasa Sains. Bandung.

[9] Munir, Rinaldi. 2005. Matematika Diskrit. Edisi ketiga. Informatika Bandung. Bandung.

[10] Udjiani, Titi. 2004. Invers Matriks Moore Penrose Atas Ring Komutatif dengan Elemen Satuan. Vol.7. No. 1. 20-30. Program Studi Matematika FMIPA. Universitas Diponegoro. Semarang. 